\title{
Pneumatosis Cystoides Intestinalis: A Rare Cause of Pneumoperitoneum in Children
}

\author{
Khan SUDE ${ }^{1}$, Harun $\mathrm{HR}^{2}$, Nessa $\mathrm{M}^{3}$, Hasan $\mathrm{K}^{4}$
}

\begin{abstract}
Pneumatosis Cystoides Intestinalis $(\mathrm{PCl})$ is a rare disease characterized by presence of air-filled cysts in the gastrointestinal wall. The incidence of $\mathrm{PCl}$ is unknown as most of the patients are asymptomatic. Rarely, patients may experience symptoms secondary to the cysts. The pathogenesis of $\mathrm{PCl}$ is still unclear and as such many theories are proposed. Usually, no treatment is necessary for $85 \%$ of patients who are asymptomatic. Surgery may be required for complications.
\end{abstract}

Key-words: Pneumatosis Cystoides Intestinalis $(\mathrm{PCl})$, air-filled cysts, gastrointestinal tract.

\section{Introduction}

Pneumatosis Cystoides Intestinalis $(\mathrm{PCl})$ is a rare condition characterized by the presence of air-filled cysts present in the bowel wall and mesentery and may occur anywhere in the gastrointestinal tract. The cysts $(0.5-10 \mathrm{~cm}$ in size) are found most frequently in the terminal ileum and rarely in the proximal small bowel, stomach, and colon ${ }^{1}$. The cysts usually contain nitrogen, hydrogen and carbon dioxide and are located beneath the serosa and mucosa of the intestine $^{2} . \mathrm{PCl}$ itself is not a disease, rather a clinical $\operatorname{sign}^{3}$. These subserosal and submucosal air-filled blebs may be a benign finding with no apparent precipitating cause. Alternatively, they may be a manifestation of any of a wide variety of serious medical conditions, including gastrointestinal infection, inflammatory bowel disease, progressive systemic sclerosis, life-threatening intraabdominal catastrophe (e.g., bowel infarction or an underlying malignant condition), organ transplantation, and obstructive lung disease ${ }^{4,5}$. The incidence $\mathrm{PCl}$ is unknown due to the asymptomatic course of the disease in most cases. The frequency is reported to be highest in the sixth decade. Primary (Idiopathic) and secondary forms of the disease are described. Primary $\mathrm{PCl}$ is extremely rare. The underlying conditions for secondary $\mathrm{PCl}$ are divided into six groups, traumatic and mechanical, inflammatory and autoimmune, infectious, pulmonary, drug induced and other ${ }^{6,7}$. The exact aetiology of the disease is still unclear. $\mathrm{PCl}$ may appear in association with ileal surgery, colonoscopies, chronic pulmonary disease, connective tissue disorders and ingestion of sorbitol or lactulose $e^{8,9}$. When the airfilled cysts rupture, they cause a pneumoperitoneum, which often is benign in nature but creates a diagnostic dilemma.

There is no characteristic clinical presentation of $\mathrm{PCl}$. Patients may be asymptomatic, diagnosed incidentally or complain of pain and abdominal distension, diarrhoea and rectal blood loss with a mortality rate ${ }^{10}$ that may reach $75 \%$. The purpose of this study is the development of awareness about this rare disease which may present with pneumoperitoneum and to appraise about treatment options.

\section{Case Report}

An 11-year-old boy was admitted to a peripheral military hospital with complaints of gradual distension of abdomen for 8 days. He was a known case of Down's syndrome with mental retardation (Fig-1). There was no history of fever, vomiting, constipation or abdominal pain. He had features of common cold earlier, temperature was normal, pulse rate 60/ minute. Abdominal examination revealed distended abdomen which was soft and nontender, bowel sound was present. X-ray chest suggestive of pneumothorax (Rt) (Fig-2). Plain X-ray abdomen revealed pneumoperitoneum with loops of distended bowel (Fig-3). Ultrasonogram (USG) showed moderate

1. Col Shams-ud-Din Elias Khan, MBBS, MS (Paed Surgery), Classified Spl in Surgery (Paed), CMH, Dhaka

2. Maj Gen H R Harun, MBBS, FCPS, FRCS (Edin\&Glasg), DUro (London), Ex Consultant Surgeon General, Bangladesh Armed Forces, Dhaka 3. Col Meherun Nessa, MBBS, MS (Paed Surgery), Adviser Specialist in Paediatirc Surgery, CMH, Dhaka 4. Capt Khaled Hasan, MBBS, Trainee in Surgery, CMH, Dhaka. 
ascites with dilated aperistaltic bowel loops. The patient managed conservatively and transferred to tertiary level military hospital where Paediatric Surgery facilities are available. On arrival he was reviewed by Paediatric Surgeon and Thoracic Surgeon. Repeat X-ray chest, X-ray abdomen, USG of abdomen showed similar finding. CT scan of chest and abdomen showed congenital lobar emphysema of right upper lobe, pneumoperitoneum with distended loops of bowel. Routine biochemical reports were within normal limit.

He underwent laparotomy and the findings were clear ascitic fluid, both the small and large bowel were distended at places and contained variable sized serosal air cysts involving long segment of ileum, ascending colon and left colic flexure without any perforation (Fig-4\&5). Some cysts ruptured, resulted in pneumoperitoneum. Portion of ileum with doubtful viability was excised and end to end anastomosis was done and the specimen was sent for histopathology. Abdomen was closed in layers after putting a drain in pelvis. Post operative recovery was uneventful. Histopathology revealed pneumatosis cystoides intestinalis (Fig-6).

\section{Discussion}

Pneumatosis cystoides intestinalis $(\mathrm{PCl})$ is defined as air filled cysts within the wall of the gastrointestinal tract. It was first described by $\mathrm{Du}$ Vernoi $^{1,6}$ in a cadaveric dissection in 1783 and in 1899 Hahn described $\mathrm{PCl}$ living patients ${ }^{11}$. The presenting clinical picture may be very heterogeneous representing a challenge for the clinician ${ }^{2}$. All parts of the gastrointestinal tract may be affected; the small bowel is involved in $42 \%$, the colon in $36 \%$ or both in $22 \%$ of the cases ${ }^{12}$. Primary $\mathrm{PCl}$ is an uncommon condition, in most cases $\mathrm{PCl}$ is due to an underlying disease or condition (traumatic and mechanical, inflammatory and autoimmune diseases, drug induced, immunosuppression, transplantation or neoplasm) $)^{13}$. Although this condition is usually asymptomatic and incidentally found during radiological evaluation or laparotomy, it can be a cause of pneumoperitoneum or obstruction. Clinical signs and imaging features in these situations may mimic true abdominal viscera perforation, so a correct diagnosis is imperative as treatment of $\mathrm{PCl}$ is generally conservative ${ }^{1}$.

Approximately $3 \%$ of afflicted patients experience a complication, such as pneumoperitoneum, volvulus, intestinal obstruction, intussusceptions, haemorrhage or perforation ${ }^{6}$.

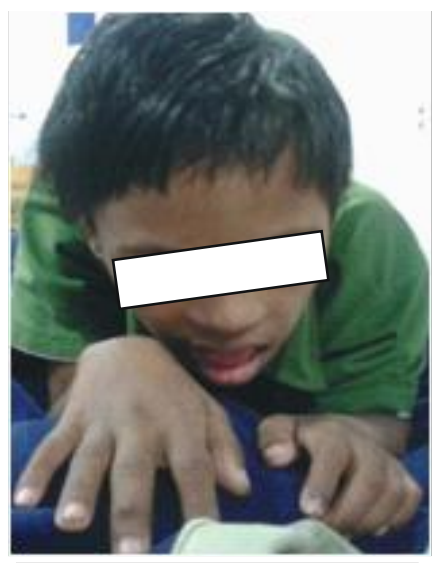

Fig-1: The patient with PCI with Down's syndrome and mental retardation

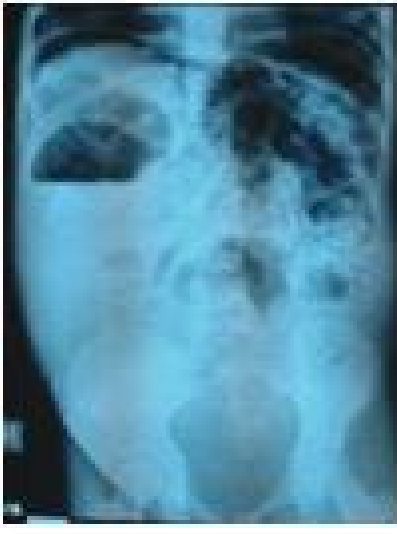

Fig-3: X-ray abdomen showing pneumoperitoneum with dilated loops of intestine

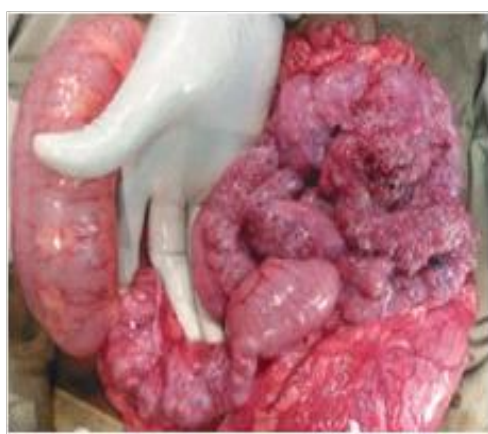

Fig-5: Serosal air cyst with distended bowel on exploration

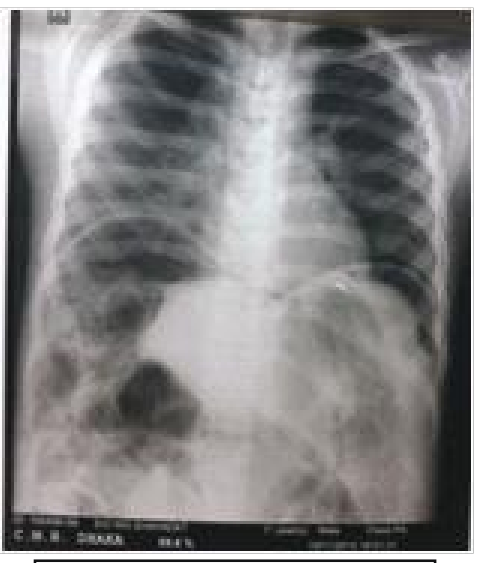

Fig-2: X-Ray Chest showing pneumoperitoneum and pneumothorax

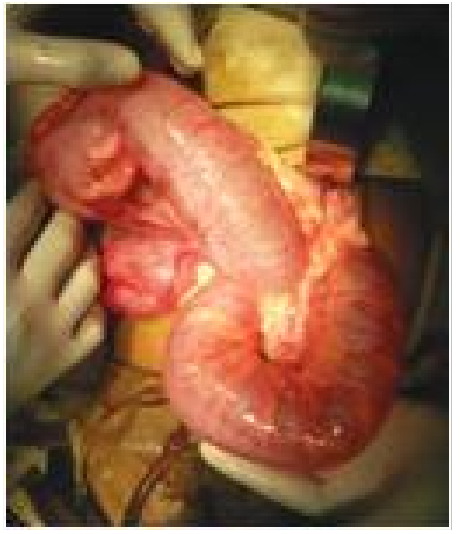

Fig-4: Distended bowel loops on exploration

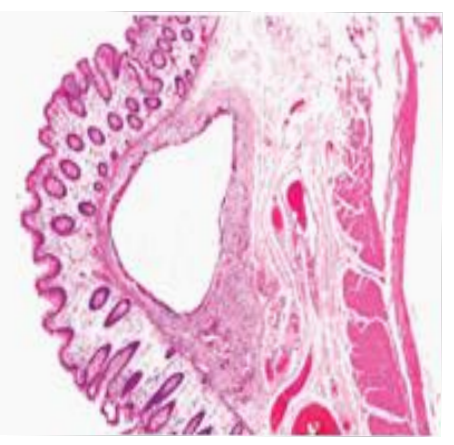

Fig-6: Microscopic view of pneumatosis cystoides intestinalis showing cystic spaces 
The pathogenesis of $\mathrm{PCl}$ is still unclear and multiple theories have been proposed: mechanical, bacterial and pulmonary ${ }^{2}$. Two basic mechanical features are responsible for intrusion of intraluminal gas into the bowel wall: mucosal injury, the most important and prevalent feature, and increased intraluminal pressure; or both ${ }^{6}$. Here the bowel gas is pushed through a mucosal defect into lymphatic channels and is then distributed distally by peristalsis. Increased intraluminal pressure may be produced by bowel obstruction, ileus, or iatrogenically by upper or lower GI endoscopy. Damages in the mucosa may result from an inflammatory process, a defect in the gut immune barrier and steroid or cytotoxic medical therapy. This could explain the association between these manoeuvres and $\mathrm{PCl}$. However, this theory does not explain the high content of hydrogen present in the cysts ${ }^{2,6}$.

According to bacterial theory submucosal localization of fermenting Clostridia and Escherichia coli leads to production of gas which is retained by the submucosa and lymphatic channels. Mucosal damage and immune deficiency leads to bacterial invasion of intramural compartments. Bacteria produce intraluminal hydrogen tension higher than nitrogen tension in blood leading to hydrogen diffusion towards the submucosal vessels, where it is followed by nitrogen, oxygen and carbon dioxide from circulation ${ }^{2,6}$. This theory is also supported by the resolution of pneumatosis with the use of metronidazole for bacterial growth ${ }^{1,2,6}$.

The pulmonary theory for $\mathrm{PCl}$ is based on the observation of air migration along vessels within the mediastinum, retroperitoneum and mesentery after alveolar rupture in pulmonary diseases ${ }^{6}$. Some recent reports mentioned an association between $\mathrm{PCl}$ and treatment with alpha-glucosidase inhibitor. The explanation would be the fermentation of excess carbohydrates caused by these drugs by the intestinal bacterial flora with production of intestinal gas $^{2,6}$. Plain radiography, barium enema, ultrasound, abdominal CT and endoscopy can be helpful in diagnosing $\mathrm{PCl}^{6}$. Plain X-ray of the digestive tract may show a change in the characteristics of the intestinal wall in two-thirds of these patients leading to further investigations. Findings on plain radiography may reveal radiolucent linear or bubbly circular air bubbles in the bowel wall, with or without free gas accumulation in the peritoneal cavity ${ }^{1,2}$. In this case plain X-ray showed bubbly circular air bubbles in the bowel wall with pneumoperitoneum. However, one third of the patients do not have a suggestive X-ray and require a CT scan/magnetic resonance imaging, showing a thickened bowel wall containing gas to confirm the diagnosis ${ }^{14}$. CT imaging is considered as the gold standard procedure for the diagnosis of $\mathrm{PCl}$. Furthermore, CT allows the detection of additional findings that may suggest an underlying potentially worrisome cause of $\mathrm{PCl}$ such as bowel wall thickening, altered contrast mucosal enhancement, dilated bowel, soft tissue stranding, ascites, and the presence of portal air ${ }^{1}$. The endoscopic appearance of $\mathrm{PCl}$ is typically dual: multiple white small cysts coupled with a sub-atrophic mucosa or larger cysts (up to $3 \mathrm{~cm}$ ) with a reddened overlying mucosa ${ }^{2}$.

Treatment of $\mathrm{PCl}$ ranges from supportive care to laparotomy. Surgical therapy is still a second-line therapy, chosen especially for complications, the first approach is oxygen therapy ${ }^{1,2}$. $\mathrm{PCl}$ is often benign and only conservative treatment, and follow up is required. Laparotomy should not be performed based on radiographic findings alone. Good results with oxygen therapy have been reported in $\mathrm{PCl}$. Pneumoperitoneum is not necessarily caused by bowel perforation but may represent a ruptured cyst $^{15}$. Gas in the portal system is associated with a high mortality rate of $37 \%$ and often occurs with ischaemic bowel. With laboratory findings of elevated CRP or white blood cell count, as well as signs of sepsis, bowel perforation or free gas near the portal vein immediate surgery is indicated ${ }^{2,6}$. In this case, patient presented with pneumoperitoneum, moderate ascites with aperistaltic bowel indicating the need for laparotomy. Laparotomy revealed portion of ileum of doubtful viability requiring excision with end to end anastomosis. Here both ileum and large bowel were affected which occurs in $22 \%$ of cases.

\section{Conclusion}

$\mathrm{PCl}$ is a rare disease with heterogeneous presentation, often creating a diagnostic dilemma. The clinicians should be aware of the possible diverge presentations of $\mathrm{PCl}$ in order to correctly manage the patients affected with this disease and avoid unnecessary surgeries. A laparotomy without clear indication might 
even worsen the general condition of the patient. It is possible that with the increasing number of colonoscopies performed for colon cancer screening $\mathrm{PCl}$ is casually encountered and/or provoked.

\section{References}

1. Devgun P, Hassan H. Pneumatosis Cystoides Intestinalis: A Rare Benign Cause of Pneumoperitoneum. Case Reports in Radiology. Volume 2013, Article ID 353245, Available at: http://dx.doi.org/10. $1155 / 2013 / 353245$.

2. Azzaroli F, Turco L, Ceroni L et al. Pneumatosis cystoides intestinalis. World J Gastroenterol 2011 Nov 28; 17(44):4932-6.

3. Pneumatosis intestinalis. Available at: en.wikipedia. org/wiki/pneumatosis_intestinalis.

4. Sheng Wu S, Heng Yen H. Pneumatosis Cystoides Intestinalis. N Engl J Med 2011; 365:e16 August 25, 2011.

5. Lock G, Holstege A, Lang B, Schölmerich J. Gastrointestinal manifestations of progressive systemic sclerosis. American Journal of Gastroenterology 1997; 92(5):763-71.

6. Schropfer E, Meyer T. Surgical aspects of pneumatosis cystoides intestinalis: two case reports. Cases Journal 2009; 2:6452 doi:10.4076/1757-1626 -2-6452.

7. Shawn DP, Maher AA, Keith AK. The spectrum of pneumatosis intestinalis. Arch Surg 2003; 138: 68-75.
8. McCollister DL, Hammerman HJ. Air, air, everywhere: pneumatosis cystoides coli after colonoscopy. Gastrointest Endosc 1990; 36:75-6.

9. Duncan B, Barton LL, Eicher ML, Chmielarczyk VT, Erdman SH, Hulett RL. Medication-induced pneumatosis intestinalis. Pediatrics 1997; 99:633-6.

10. Knechtle SJ, Davidoff AM, Rice RP. Pneumatosis intestinalis. Surgical management and clinical outcome. Ann Surg 1990; 212:160-5.

11. Hahn E. Ueber Pneumatosis cystoidesintestinorumhominis und einendurch Laparotomiebehandelten Fall. Dtsch Med Wochenschr 1899; 25:657-60.

12. Hoer J, Truong S, Virnich $\mathrm{N}$ et al. Pneumatosis cystoides intestinalis: confirmation of diagnosis by endoscopic puncture a review of pathogenesis, associated diseases and therapy and a new theory of cyst formation. Endoscopy 1998;30:793-9.

13. Baumann C, Menenakos C, Jacobi CA. Pneumatosis intestinalis-a pitfall for surgeons? Scand J Surg (Finland) 2005, 94:47-50.

14. Ho LM, Paulson EK, Thompson WM. Pneumatosis intestinalis in the adult: benign to life-threatening causes. AJR Am J Roentgenol 2007; 188:1604-13.

15. D'Agostino S, Fabbro MA, Musi L et al. Pneumatosis cystoides intestinalis: A rare cause of nonsurgical pneumoperitoneum in an infant. J Pediatr Surg 2000; 35:1106-8. 